\title{
TRANSFORMAÇÃO DE FASE NO RESFRIAMENTO APÓS A LAMINAÇÃO A QUENTE DE AÇOS PROPENSOS À OVALIZAÇÃO DE BOBINAS*
}

\author{
Priscila Batista Dias Santos ${ }^{1}$ \\ Túlio Magno Fuzessy de Melo² \\ Marcio Hermanno Hermisdorff ${ }^{3}$
}

\section{Resumo}

A ovalização é uma alteração indesejável na forma de bobinas laminadas a quente (BQs), que pode ocorrer durante seu resfriamento e que dificulta o processamento posterior. Esse fenômeno pode estar relacionado a diversos fatores, entre os quais se destacam, especialmente em aços com carbono equivalente mais alto, alterações associadas à decomposição da austenita durante o resfriamento da BQ. Neste estudo foi investigado, utilizando simulações por dilatometria, o efeito das condições de resfriamento após a laminação a quente nas transformações de fase de aços CMn propensos à ovalização. Os resultados obtidos mostraram que as condições de resfriamento afetam não só a microestrutura final, mas também a cinética de decomposição da austenita dos aços avaliados, indicando que é possível reduzir o índice de ocorrência de ovalização de BQs desses aços por meio de alterações na temperatura de bobinamento.

Palavras-chave: Laminação a quente; Transformações de fase; Defeito ovalização.

\section{PHASE TRANSFORMATION ON COOLING AFTER HOT ROLLING OF STEELS PRONE TO COIL COLLAPSE}

\section{Abstract}

Coil collapse is an undesirable shape change of hot rolled coils during cooling, which hampers its further processing. This phenomenon can be related to several factors, among which, especially in steels with high carbon equivalent, changes associated to the austenite decomposition during coil cooling. The effect of cooling conditions after hot rolling on the phase transformations was investigated in C-Mn steels prone to coil collapse, using dilatometry simulations. The results showed that cooling parameters affect not only the final product microstructure but also the austenite decomposition kinetics, indicating that it is possible to decrease the occurrence of coil collapse by means of changes in the coiling temperature.

Keywords: Hot rolling, Phase transformation, Coil collapse.

1 Engenheira Metalurgista, Técnica de Pesquisa do Centro de P\&D da Usiminas, Ipatinga, MG.

2 Engenheiro Mecânico, Dr.-Ing., Pesquisador Especialista Sênior do Centro de P\&D da Usiminas, Ipatinga, MG.

3 Técnico em Metalurgia, Técnico em Gestão da Laminação a Quente da Usiminas, Ipatinga, MG. 


\section{INTRODUÇÃO}

A produção de aços planos laminados a quente com espessuras inferiores a cerca de $15 \mathrm{~mm}$ é geralmente realizada em linhas de laminação de tiras a quente. No final do processo, na região mostrada em destaque no esquema da figura 1, a tira laminada passa por uma mesa de resfriamento forçado, com água, e segue para uma bobinadeira, onde é acondicionada na forma de uma bobina a quente (BQ). Após o bobinamento, geralmente realizado entre $500^{\circ} \mathrm{C} \mathrm{e} 700^{\circ} \mathrm{C}$, a $\mathrm{BQ}$ é retirada da linha e resfria naturalmente até atingir a temperatura ambiente [1].

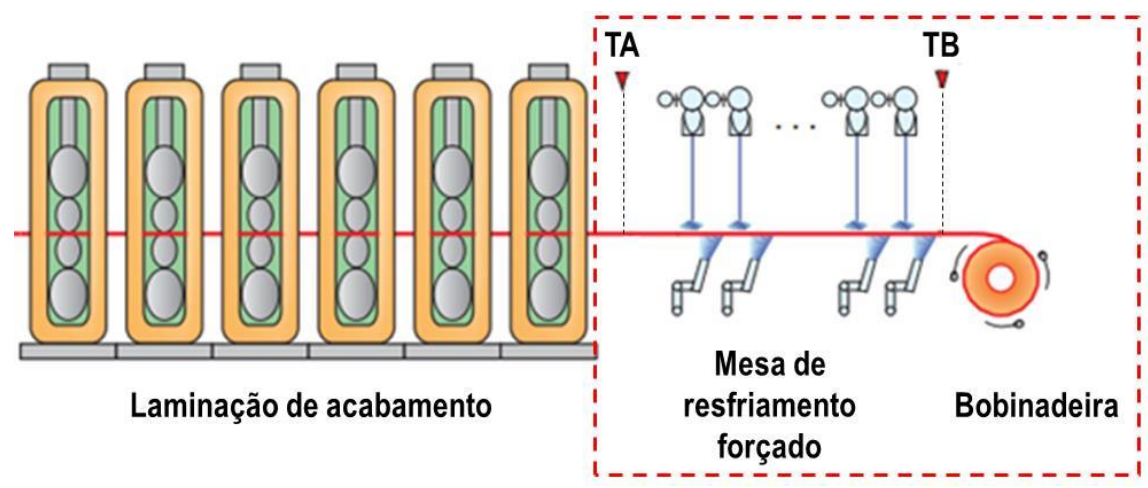

Figura 1. Esquema típico da fase de acabamento de uma Linha de Tiras a Quente, destacando a mesa de resfriamento forçado entre a laminação de acabamento e a bobinadeira.

O manuseio e a estocagem da $\mathrm{BQ}$ após o bobinamento podem ser realizados com seu eixo na posição horizontal ou vertical. Embora seja usada para evitar danos nas bordas da tira, a posição horizontal favorece a ocorrência do defeito conhecido como ovalização [2,3], cujo aspecto é mostrado na Figura 2. Trata-se de uma alteração de forma da $B Q$ resultante da perda de sua rigidez estrutural durante o resfriamento, que pode dificultar seu processamento posterior. A necessidade de retrabalho ou desclassificação da $\mathrm{BQ}$ é definida em função do grau de deformação sofrido pelo seu diâmetro interno, que pode ser medido de diversas formas [4]. Na Usiminas, a intensidade da ovalização é dada pela diferença entre os comprimentos do maior e do menor eixo interno da $B Q$.

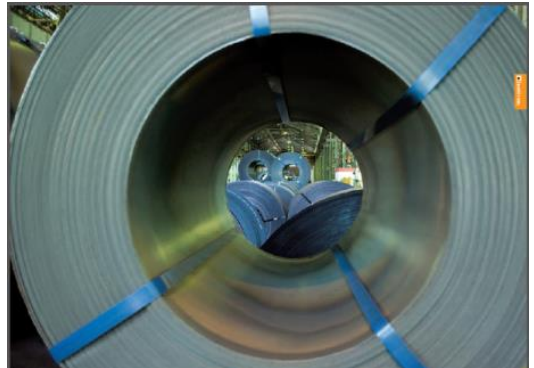

(a) Normal

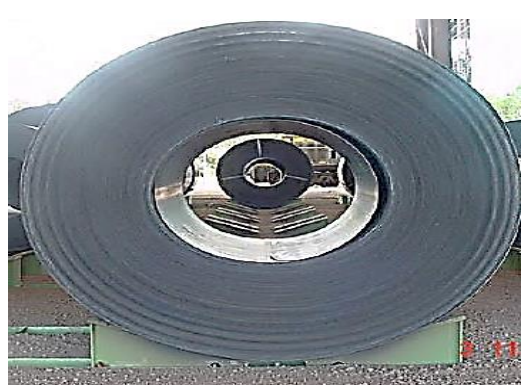

(b) Com ovalização

Figura 2. Exemplo de bobinas laminadas a quente (a) sem defeito geométrico e (b) com o defeito ovalização.

Diversos trabalhos têm mostrado que a ovalização é afetada por fatores, tais como, o peso da bobina, a espessura da tira, o limite de escoamento do material à alta temperatura, a tensão de bobinamento e o atrito entre as espiras [2-6]. Do ponto de vista metalúrgico, a transformação da austenita em ferrita/perlita que ocorre após a laminação tem três efeitos que também podem facilitar a deformação do material e provocar ovalização. Em primeiro lugar, como a ferrita é mais macia que a austenita, 
a transformação pode provocar perda de rigidez da BQ. Além disso, o calor gerado pela transformação também pode aumentar a temperatura da $B Q$, reduzindo ainda mais sua dureza e rigidez estrutural. Finalmente, a transformação de fases é acompanhada de uma dilatação no material, que pode aumentar o nível das tensões internas na BQ.

Em grande parte dos aços C-Mn processados na Linha de Tiras a Quente, a transformação da austenita praticamente se completa na mesa de resfriamento, antes do bobinamento [1]. Todavia, em alguns aços, especialmente aqueles com carbono equivalente mais alto, a transformação de fase começa a uma temperatura $\left(\mathrm{Ar}_{3}\right)$ próxima da temperatura de bobinamento e continua durante o resfriamento do material já bobinado, podendo até ocorrer totalmente após o bobinamento [5,6]. Portanto, torna-se fundamental investigar a evolução das transformações de fases nesses aços, já que elas podem contribuir para a ocorrência de ovalização.

A análise da decomposição da austenita é geralmente realizada através de diagramas de transformação no resfriamento contínuo (TRC), que mostram as temperaturas de formação de fases ao longo de resfriamentos realizados com uma ampla gama de velocidades constantes. Embora sejam úteis para uma análise preliminar, esses diagramas não reproduzem condições específicas do processo industrial, tais como, por exemplo, variações na temperatura de bobinamento (TB) e quedas bruscas na velocidade de resfriamento após o bobinamento [1]. $\mathrm{O}$ objetivo deste estudo foi avaliar, através de simulações em escala de laboratório, a influência dessas condições sobre as transformações de fase de aços $\mathrm{C}-\mathrm{Mn}$ propensos à ovalização de BQs, visando fornecer subsídios para possíveis ajustes no processo de forma a reduzir a ocorrência desse defeito.

\section{MATERIAIS E MÉTODOS}

\subsection{Materiais}

Para a realização do estudo foram selecionados três aços C-Mn que apresentam alto índice de ovalização de bobinas, cuja composição química básica é apresentada na tabela 1. As amostras foram retiradas de BQs produzidas em escala industrial com espessuras entre $2,3 \mathrm{~mm}$ e 3,0 $\mathrm{mm}$. Na tabela 1 também é indicado o valor de carbono equivalente (CE) de cada aço, calculado de acordo com a equação 1 [7].

Tabela 1. Composição química dos aços estudados [\% em massa]. CE = carbono equivalente, calculado de acordo com a equação (1).

\begin{tabular}{c|c|c|c}
\hline Aço & C & Mn & CE \\
\hline A & 0,05 & 0,23 & 0,09 \\
\hline B & 0,07 & 2,00 & 0,40 \\
\hline C & 0,14 & 2,03 & 0,48 \\
\hline \hline
\end{tabular}

$$
\mathrm{CE}=\% \mathrm{C}+\left(\frac{\% \mathrm{Mn}}{6}\right)
$$




\subsection{Ensaios dilatométricos}

Os aços aqui avaliados, listados na tabela 1, são processados na Linha de Tiras a Quente sob condições similares. Tipicamente, a tira sai da última cadeira da laminação de acabamento a cerca de $880^{\circ} \mathrm{C}(\mathrm{TA})$, sofre um resfriamento forçado com água, a uma taxa média de $25^{\circ} \mathrm{C} / \mathrm{s}$, e entra na bobinadeira em torno de $650^{\circ} \mathrm{C}$ (TB). No presente estudo, foi investigado o efeito de alterações nesse perfil de resfriamento sobre a evolução das transformações de fases desses aços. Para isso, variou-se a taxa de resfriamento forçado, mantendo-se constante a $\mathrm{TA}\left(880^{\circ} \mathrm{C}\right)$ e a velocidade da tira, de forma a simular diferentes valores de TB, entre $650^{\circ} \mathrm{C}$ e $500^{\circ} \mathrm{C}$, como indicado esquematicamente na figura 3 .

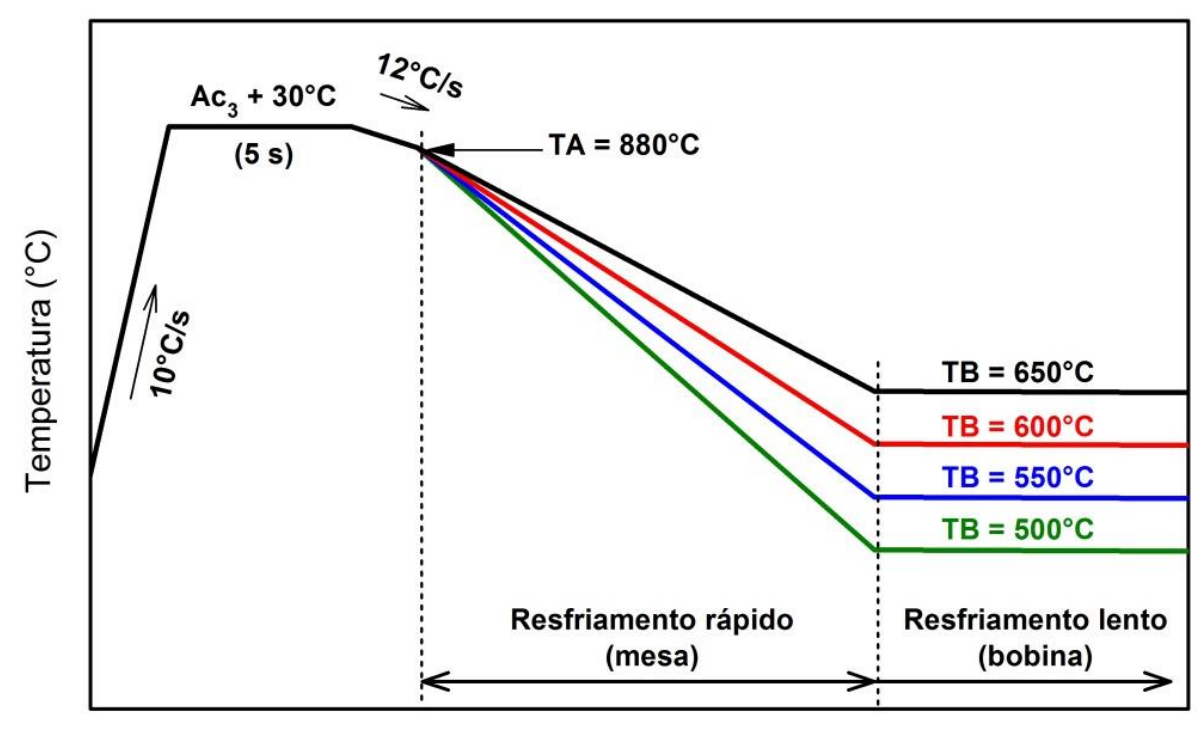

Tempo (s)

Figura 3. Representação esquemática dos ciclos térmicos aplicados nos ensaios dilatométricos.

Os ensaios foram realizados no Dilatômetro Bähr DIL805 do Centro de Pesquisa e Desenvolvimento da Usiminas. Foram preparados corpos de prova (cps) planos, retirados das amostras de BQs, com o comprimento de $10 \mathrm{~mm}$ (paralelo à direção de laminação), largura de $4 \mathrm{~mm}$ e espessura original da amostra. Conforme mostrado na figura 3 , os cps foram aquecidos a $10^{\circ} \mathrm{C} / \mathrm{s}$ até $30^{\circ} \mathrm{C}$ acima da temperatura $\mathrm{Ac}_{3}$, medida preliminarmente para cada material. Após um encharque de $5 \mathrm{~s}$, para homogeneização térmica, os $\mathrm{cps}$ foram resfriados até $880^{\circ} \mathrm{C}$ (TA), com taxa de $12^{\circ} \mathrm{C} / \mathrm{s}$, e então submetidos ao perfil de resfriamento forçado correspondente a cada valor de TB visado. A partir daí, foi aplicado um resfriamento lento $\left(0,1^{\circ} \mathrm{C} / \mathrm{s}\right)$ até a temperatura ambiente, simulando a evolução térmica do material após 0 bobinamento. As etapas de aquecimento e encharque foram realizadas sob vácuo, e para os resfriamentos foi utilizado gás nitrogênio.

\subsection{Análise das curvas dilatométricas}

Durante os ensaios dilatométricos, o aquecimento e o resfriamento são controlados através de um termopar de Pt-Pt/Rh fixado na superfície do $\mathrm{cp}$, cujo comprimento é medido por um transdutor LVDT de alta precisão. Os valores de temperatura e comprimento obtidos ao longo de cada ensaio geram uma curva dilatométrica, similar à mostrada na figura 4 , correspondente ao resfriamento de um dos ensaios 
realizados. Conforme indicado nessa figura, as temperaturas de início $\left(\mathrm{Ar}_{3}\right)$ e fim $\left(\mathrm{Ar}_{1}\right)$ de transformação de fases foram determinadas pelo desvio da curva em relação às retas correspondentes à austenita e aos constituintes presentes na microestrutura final $[8,9]$. A fração de austenita transformada ao longo de cada resfriamento também foi estimada com base nessa curva, aplicando-se o método da alavanca, mostrado esquematicamente na Figura 4.

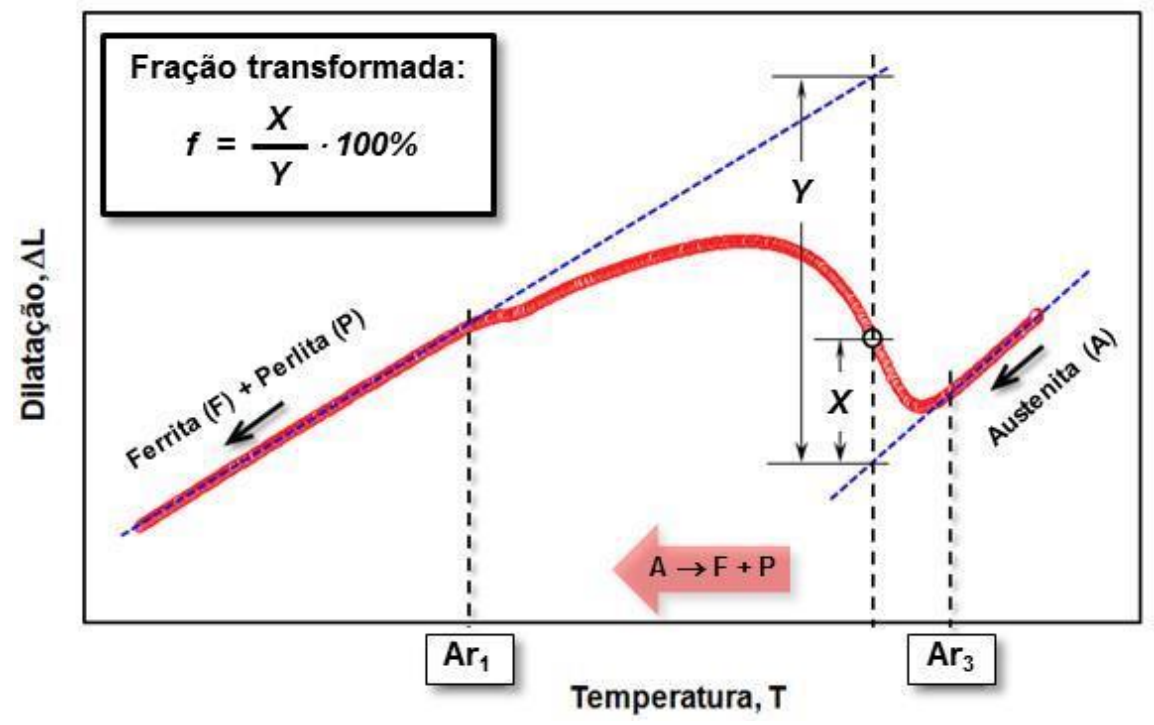

Figura 4. Exemplo de uma curva dilatométrica obtida no resfriamento, indicando as temperaturas de início $\left(A r_{3}\right)$ e fim $\left(A r_{1}\right)$ de transformação da austenita e aplicação do método da alavanca para a determinação da fração transformada.

\subsection{Caracterização microestrutural e de dureza}

A microestrutura de cada $\mathrm{cp}$ ensaiado foi caracterizada em uma seção paralela ao seu comprimento, no meio de sua largura, após preparação metalográfica convencional e ataque com reativo Nital 4\%. Nessas mesmas seções também foi medida a dureza Vickers do material, usando carga de $5 \mathrm{kgf}$.

\section{RESULTADOS E DISCUSSÃO}

\subsection{Efeito da TB sobre a decomposição da austenita no resfriamento}

A evolução da transformação da austenita ao longo dos resfriamentos simulados, para os três aços avaliados, é apresentada na figura 5. Nessa figura, são mostradas as curvas de fração transformada com o tempo desde a temperatura de acabamento (TA), incluindo sua passagem na mesa de resfriamento forçado e alguns segundos após o bobinamento. Observa-se, de maneira geral, que a redução da TB, realizada através do aumento da taxa de resfriamento forçado anterior ao bobinamento, adiantou o início e acelerou a decomposição da austenita, notadamente para os aços $B$ e $C$. No caso do aço $A$, a redução da TB praticamente não afetou o início da transformação, apenas aumentou levemente sua velocidade. Para qualquer uma das três condições testadas nesse aço $\left(\mathrm{TB}=650^{\circ} \mathrm{C}, 600^{\circ} \mathrm{C}\right.$ ou $\left.550^{\circ} \mathrm{C}\right)$ a decomposição da austenita começou e terminou na mesa de resfriamento forçado, antes da entrada da tira na bobinadeira. Esse resultado sugere, portanto, que a ovalização de BQs desse aço não deve estar relacionada à transformação de fases após o 
bobinamento, mas sim a outros fatores mencionados anteriormente, que também podem estar afetando sua rigidez estrutural.

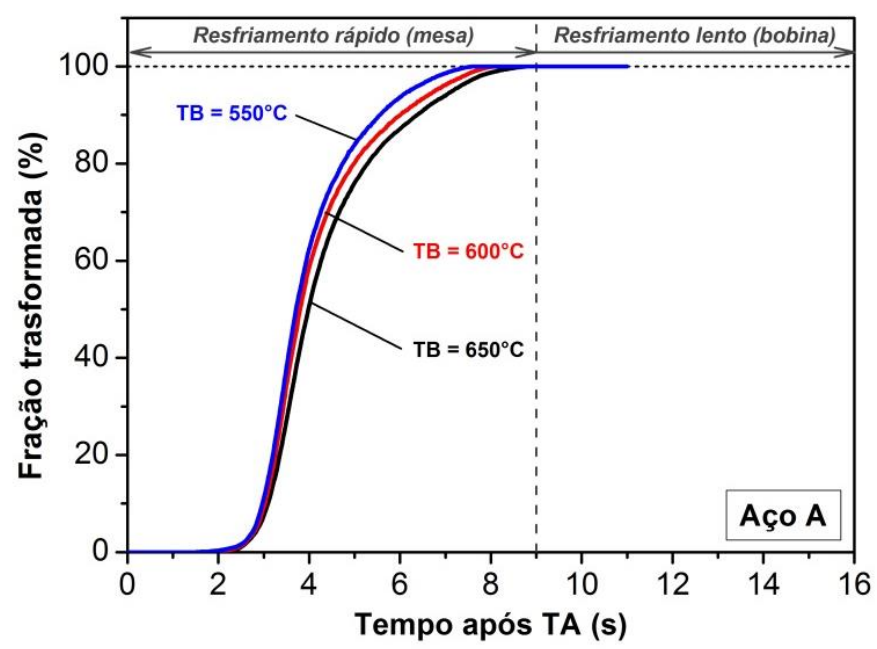

(a)

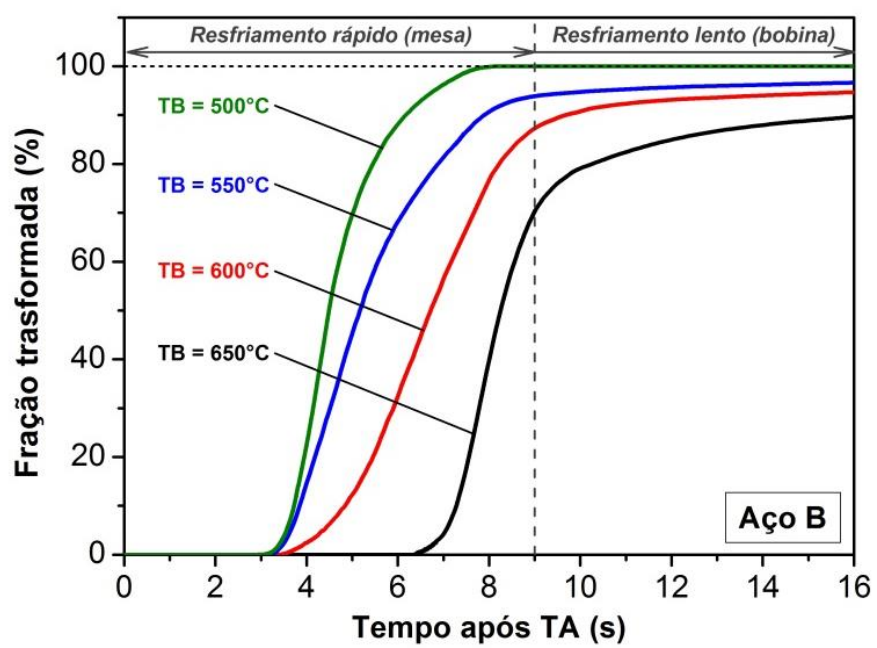

(b)

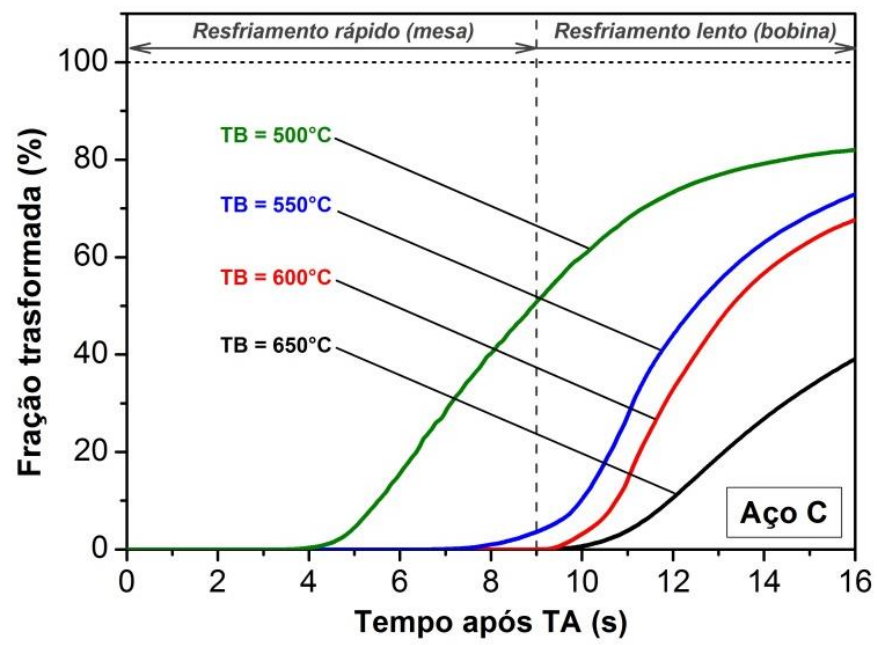

Figura 5. Fração de austenita transformada ao longo do tempo de resfriamento a partir da temperatura de acabamento (TA) para as condições simuladas ( $T B=$ temperatura de bobinamento).

Nota-se na figura 5 que a redução da TB deslocou a transformação de fase do aço $B$ para a mesa de resfriamento. Para $\mathrm{TB}=650^{\circ} \mathrm{C}$, a transformação atingiu cerca de 
$70 \%$ do volume do material antes do bobinamento. Nesse caso, o amaciamento e a variação dimensional gerados pela transformação dos $30 \%$ restantes do volume podem explicar, pelo menos em parte, a maior tendência de ovalização observada em bobinas desse aço com TB mais altas. Para as TBs de $600^{\circ} \mathrm{C}$ e $550^{\circ} \mathrm{C}$, a fração transformada antes do bobinamento chegou a $90 \%$ e $95 \%$, respectivamente, atingindo $100 \%$ do volume do material bobinado a $500^{\circ} \mathrm{C}$.

No caso do aço $\mathrm{C}$, a transformação de fases só teve início após o bobinamento para TB de $650^{\circ} \mathrm{C}$ ou $600^{\circ} \mathrm{C}$. Para TB $=550^{\circ} \mathrm{C}$, registrou-se apenas cerca de $5 \%$ do volume do material transformado no final da mesa de resfriamento forçado. Já para a menor TB simulada, $500^{\circ} \mathrm{C}$, embora a decomposição da austenita tenha começado na metade da mesa de resfriamento, apenas cerca de $50 \%$ da transformação ocorreu antes do bobinamento. Os resultados obtidos mostram que a ocorrência de ovalização de $B Q s$ dos aços $B$ e $C$ pode estar relacionada à decomposição da austenita durante o resfriamento, em função das baixas temperaturas de transformação desses aços.

As temperaturas de início $\left(\mathrm{Ar}_{3}\right)$ e fim $\left(A r_{1}\right)$ de decomposição da austenita determinadas nas curvas dilatométricas obtidas nos resfriamentos simulados, para os três aços testados, são listadas na tabela 2. Verifica-se que ambas as temperaturas diminuem com a redução de TB, realizada nos ensaios dilatométricos através do aumento da taxa de resfriamento forçado. Essa tendência fica mais clara na figura 6 , onde os valores listados na tabela 2 são apresentados em função do carbono equivalente (CE) dos aços avaliados, mostrados na tabela 1. Aqui também se observa uma queda nas temperaturas críticas com 0 aumento do $C E$, independentemente da TB simulada. Esse efeito já era esperado e está de acordo com dados da literatura $[8,9]$.

Tabela 2. Temperaturas e tempos de início e fim de transformação da austenita nos ensaios realizados com os três aços avaliados, simulando diferentes temperaturas de bobinamento (TB).

\begin{tabular}{|c|c|c|c|c|c|}
\hline \multirow{2}{*}{ Aço } & \multirow{2}{*}{ TB $\left({ }^{\circ} \mathrm{C}\right)$} & \multicolumn{2}{|c|}{ Início da transformação } & \multicolumn{2}{|c|}{ Fim da transformação } \\
\hline & & $\operatorname{Ar}_{3}\left({ }^{\circ} \mathrm{C}\right)$ & $\Delta t_{i}(s)^{(1)}$ & $\operatorname{Ar}_{1}\left({ }^{\circ} \mathrm{C}\right)$ & $\Delta t_{f}(s)^{(1)}$ \\
\hline \multirow{3}{*}{$A$} & 650 & 840 & 2,0 & 652 & 8,8 \\
\hline & 600 & 839 & 1,7 & 617 & 8,2 \\
\hline & 550 & 838 & 1,5 & 594 & 7,6 \\
\hline \multirow{4}{*}{$\mathrm{B}$} & 650 & 719 & 6,4 & 576 & 547,0 \\
\hline & 600 & 704 & 3,2 & 570 & 104,0 \\
\hline & 550 & 698 & 3,1 & 544 & 73,0 \\
\hline & 500 & 688 & 3,0 & 505 & 8,0 \\
\hline \multirow{4}{*}{ C } & 650 & 693 & 9,5 & 546 & 1060,0 \\
\hline & 600 & 691 & 9,1 & 544 & 566,0 \\
\hline & 550 & 688 & 7,0 & 520 & 312,0 \\
\hline & 500 & 668 & 3,6 & 484 & 171,0 \\
\hline
\end{tabular}

(1) Tempo de resfriamento para o início $\left(\Delta \mathrm{t}_{\mathrm{i}}\right)$ e o final $\left(\Delta \mathrm{t}_{\mathrm{f}}\right)$ da transformação de fase, medidos a partir do início do resfriamento forçado $\left(T A=880^{\circ} \mathrm{C}\right)$. 


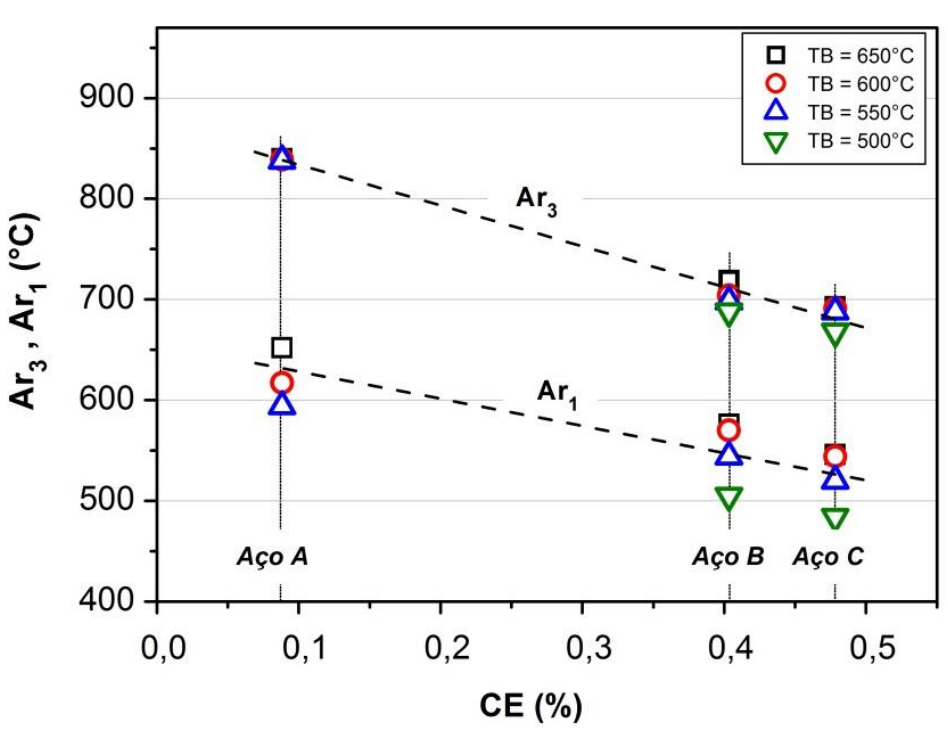

Figura 6. Efeito do carbono equivalente (CE) e da temperatura de bobinamento (TB) nas temperaturas de início $\left(\mathrm{Ar}_{3}\right)$ e fim $\left(\mathrm{Ar}_{1}\right)$ de transformação da austenita dos aços avaliados.

Na tabela 2 também está mostrado o tempo de espera até o início da transformação da austenita $\left(\Delta t_{i}\right)$, medido a partir da temperatura de acabamento TA, constante para todos os ensaios realizados. Os resultados confirmam o adiantamento do início da decomposição da austenita à medida que se aumentou a taxa de resfriamento forçado e, como consequência, reduziu-se a temperatura de bobinamento.

Esse efeito foi ainda mais drástico sobre o tempo até o final da transformação de fase $\left(\Delta t_{f}\right)$, também mostrado na tabela 2. Para o aço $B$, por exemplo, foram necessários quase 10 min após o bobinamento a $650^{\circ} \mathrm{C}$ para que a decomposição da ferrita chegasse ao fim. Por outro lado, a redução da TB para $500^{\circ} \mathrm{C}$ permitiu que toda a transformação ocorresse ainda na mesa de resfriamento forçado, antes do bobinamento. No caso do aço C, a queda da TB de $650^{\circ} \mathrm{C}$ para $500^{\circ} \mathrm{C}$ provocou uma redução de quase 15 min no tempo de transformação após o bobinamento. Deve-se ressaltar que esses intervalos de tempo devem ser muito mais longos no processamento industrial, onde a taxa de resfriamento do material na $B Q$ é bem menor que $0,1^{\circ} \mathrm{C} / \mathrm{s}$, valor usado nos ensaios dilatométricos aqui realizados [2-6].

\subsection{Microestrutura e dureza}

A alteração da taxa de resfriamento forçado, e consequentemente da TB, afeta não só a cinética de decomposição da austenita como também, a microestrutura do produto final e consequentemente, suas propriedades mecânicas. Exemplos das microestruturas típicas obtidas nos aços avaliados após os ensaios dilatométricos realizados são mostrados na figura 7 . A redução da TB de $650^{\circ} \mathrm{C}$ para $550^{\circ} \mathrm{C}$ não resultou em alteração significativa na microestrutura do aço $A$, com $C E=0,09 \%$, formada por matriz ferrítica e pequena quantidade de ilhas de perlita. De forma coerente, a dureza final também se manteve praticamente constante. No aço B, com $\mathrm{CE}=0,40 \%$, quando a TB passou de $650^{\circ} \mathrm{C}$ para $500^{\circ} \mathrm{C}$, observou-se uma pequena redução no tamanho dos grãos da ferrita e uma distribuição mais homogênea e menos alinhada da perlita. Essa alteração foi acompanhada por um aumento na dureza de $158 \mathrm{HV}$ para $176 \mathrm{HV}$. Já no aço $\mathrm{C}$, com $\mathrm{CE}=0,48 \%$, a alteração microestrutural e de dureza provocada pela redução da TB foi significativa. Para a TB de $650^{\circ} \mathrm{C}$, a microestrutura era formada por faixas de ferrita e perlita, com uma 
dureza de $179 \mathrm{HV}$. Quando o bobinamento foi realizado a $500^{\circ} \mathrm{C}$, a microestrutura apresentou-se mais refinada, com um alinhamento bem mais leve da perlita, enquanto a dureza aumentou $33 \mathrm{HV}$, passando para $212 \mathrm{HV}$.

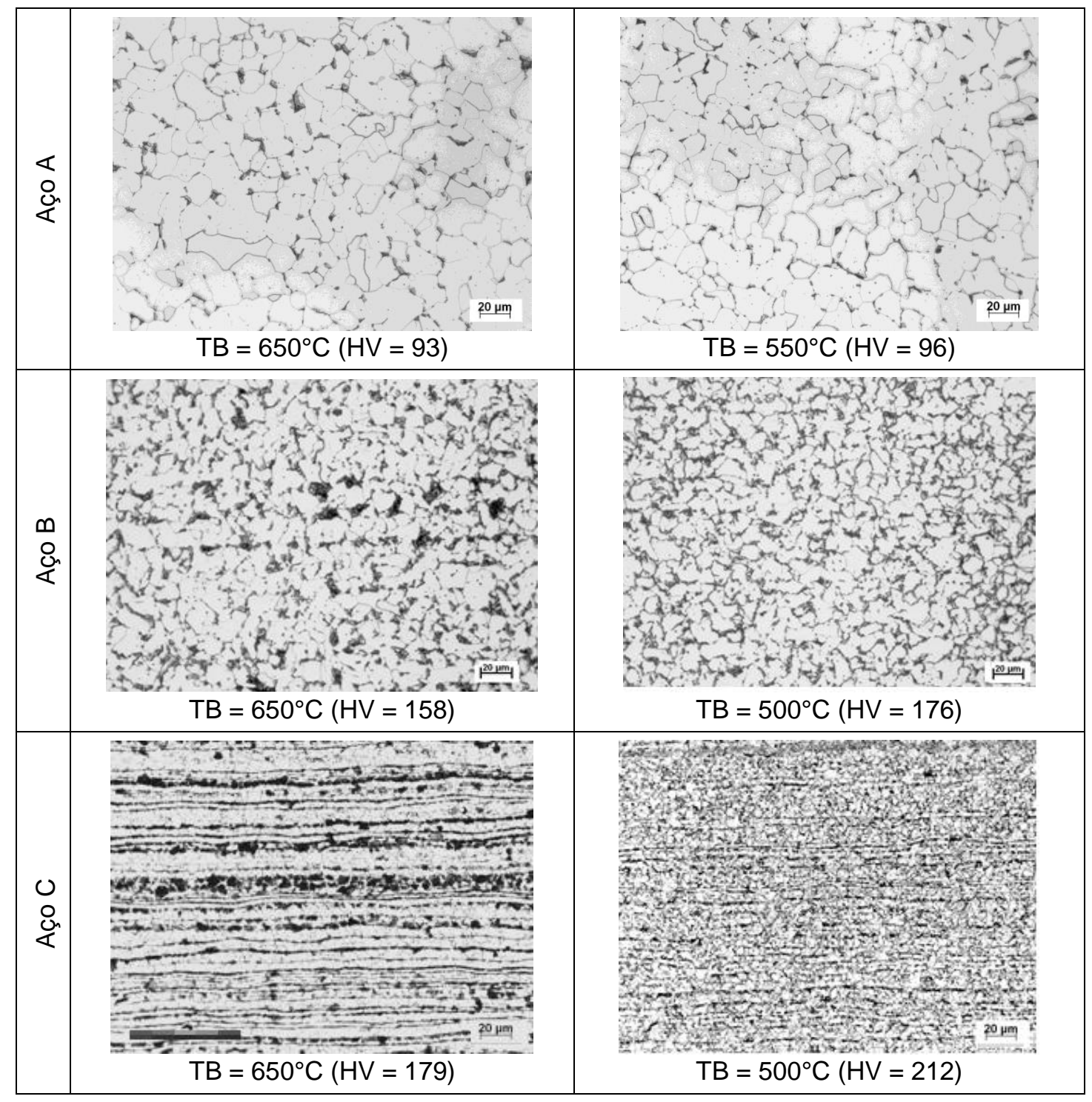

Figura 7. Efeito da temperatura de bobinamento (TB) sobre a microestrutura e a dureza Vickers (HV, com carga de $5 \mathrm{kgf}$ ) dos aços avaliados neste estudo.

\subsection{Contramedidas para redução da ovalização}

Os resultados dos ensaios dilatométricos realizados sugerem que a ocorrência de ovalização observada em BQs do aço $A$ não está relacionada a transformações de fase, já que, para todas as condições avaliadas, a decomposição da austenita ocorreu completamente na mesa de resfriamento forçado, antes do bobinamento. Verificou-se que a redução da TB de $650^{\circ} \mathrm{C}$ para $550^{\circ} \mathrm{C}$ não resultou em alterações significativas na microestrutura e na dureza finais do material.

No caso do aço B, os resultados obtidos indicaram que a transformação de fase só deve ter efeito significativo sobre a ovalização de BQs bobinadas acima de $600^{\circ} \mathrm{C}$. Para TBs entre $500^{\circ} \mathrm{C}$ e $600^{\circ} \mathrm{C}$, a fração transformada após o bobinamento foi pequena, menor que $10 \%$, e a microestrutura e a dureza finais sofreram pouca 
alteração. A partir desses resultados, foram produzidos lotes experimentais desse aço na Linha de Tiras a Quente usando uma TB em torno de $550^{\circ} \mathrm{C}$, conseguindo-se uma redução de cerca de $80 \%$ no índice de ovalização das $\mathrm{BQs}$ obtidas em relação à condição anterior $\left(\mathrm{TB}=650^{\circ} \mathrm{C}\right)$. No momento estão sendo testadas outras adaptações no processo de bobinamento com o objetivo de reduzir ainda mais a ocorrência do defeito.

Os ensaios realizados indicaram que as transformações de fases no aço $C$ aumentam sua propensão à ovalização de $\mathrm{BQs}$. A redução da $\mathrm{TB}$ de $650^{\circ} \mathrm{C}$ para $500^{\circ} \mathrm{C}$, além de não ter sido suficiente para aumentar significativamente a fração transformada antes do bobinamento, provocou uma alteração importante na microestrutura e na dureza final do material. Em função desses resultados, estão sendo realizadas experiências em escala industrial, combinando reduções possíveis da TB, em função da aplicação final dos produtos, e o controle de outras variáveis que podem afetar a ocorrência de ovalização de BQs, tais como a tensão de bobinamento, o tempo de manuseio e a posição de empilhamento.

\section{CONCLUSÃO}

Os resultados obtidos neste trabalho mostraram que a redução da TB, realizada através do aumento da taxa de resfriamento forçado anterior ao bobinamento, adiantou o início e acelerou a evolução da decomposição da austenita, em especial nos aços com carbono equivalente (CE) mais altos.

Para qualquer condição testada, a transformação do aço com CE $=0,09 \%$ começa e termina antes do bobinamento, indicando que a ocorrência de ovalização em BQs desse material não deve estar associada às transformações de fases.

No aço com $\mathrm{CE}=0,40 \%$, os resultados obtidos mostraram que a transformação de fase só deve ter efeito significativo sobre a ovalização de BQs bobinadas acima de $600^{\circ} \mathrm{C}$. Para TBs entre $500^{\circ} \mathrm{C}$ e $600^{\circ} \mathrm{C}$, a fração transformada após o bobinamento desse aço foi pequena, menor que $10 \%$, e a microestrutura e a dureza finais sofreram pouca alteração. $\mathrm{BQs}$ produzidas industrialmente com $\mathrm{TB}=550^{\circ} \mathrm{C}$ apresentaram uma redução significativa no índice de ovalização em relação à condição anterior $\left(\mathrm{TB}=650^{\circ} \mathrm{C}\right)$.

Já no caso do aço com CE mais alto $(0,48 \%)$, os ensaios realizados indicaram que a transformação de fases ocorre quase completamente após o bobinamento, o que pode estar aumentando a propensão à ovalização de BQs. A redução da TB desse aço de $650^{\circ} \mathrm{C}$ para $500^{\circ} \mathrm{C}$ não aumenta significativamente a fração transformada antes do bobinamento, mas provoca uma alteração importante na microestrutura e na dureza final do material. Estão sendo realizadas experiências em escala industrial visando à redução da ocorrência de ovalização de BQs desse aço, combinando pequenas reduções da TB e o controle de outras variáveis que podem afetar a ocorrência de ovalização de BQs, tais como a tensão de bobinamento, o tempo de manuseio e a posição de empilhamento. 


\section{REFERÊNCIAS}

1 Santos AA. Modelamento da transformação de fases de aços de alta resistência microligados ao Nb durante resfriamento após Laminação em Tiras a Quente. Tese de Doutorado, UFMG. 2007; Outubro.

2 Gorni AA, Silva MRSS. Ovalização de bobinas a quente de aços com médio teor de carbono. $51^{\circ}$ Seminário de Laminação - Processos e Produtos Laminados e Revestidos. ABM. 2014; Outubro.

3 Mazur VL, Maleshko VI, Kostyakov VV, Karetnyi ZP. Shape stability of coils of hor rolled strip. Steel in the USSR. 1987; September; (17:9): 421-424.

4 Junior SOL, Martins JBR, Prado AC, Volpato LFS, Silva CN. Redução da ovalização em bobinas a quente de um aço com CE $0,58 \%$ produzido no LTQ da CST.

5 Cho HH, Cho YG, Im YR, Lee JK, Kwak JH, Han HN. A finite element analysis for asymmetric contraction after cooling of hot-rolled steel. Journal of Materials Processing Technology. 2010; Fevereiro;(210): 907-9013

6 Banks K, Tuling A, Mintz B. Influence of chemistry and runout table parameters on hot coil collapse in C-Mn steels. Iron Making and Steelmaking. 2011: v. 38, p.204-210.

7 IIW/IIS DOC. 452-74; "Weld metal hydrogen levels and the definition of hydrogen controlled electrodes", Welding in the World 12(3/4), pp. 69-65, 1974.

8 Santos AA. Previsão das temperaturas críticas de decomposição da austenita em ferrita e perlita durante resfriamento contínuo. $41^{\circ}$ Seminário de Laminação Processos e Produtos Laminados e Revestidos. ABM. 2004; Outubro.

9 Santos AA, Melo TMF, Barbosa R. Previsão da temperatura $\mathrm{Ar}_{3}$ em aço microligado ao $\mathrm{Nb}-\mathrm{V}$-Ti. $63^{\circ}$ Congresso anual da ABM. 2008; Agosto. 